\title{
Estimation of urban water supply issues at the local scale: a participatory approach
}

\author{
Christelle Legay $^{1^{*}}$, Geneviève Cloutier ${ }^{1}$, Salem Chakhar ${ }^{2}$, Florent Joerin ${ }^{1,3}$, Manuel J. Rodriguez ${ }^{1}$ \\ ${ }^{1}$ Centre de Recherche en Aménagement et Développement, Université Laval, Québec, QC, \\ Canada ; ${ }^{2}$ Portsmouth Business School, University of Portsmouth, UK; ${ }^{3}$ Haute École d'Ingénierie \\ et de Gestion du Canton de Vaud - Yverdon, Switzerland \\ ${ }^{*}$ Corresponding author: \\ Christelle Legay, PhD \\ Tel. (418) 656-2131, ext. 4463 \\ Fax (418) 626-2018 \\ Email: christelle.legay.1@ulaval.ca
}

\begin{abstract}
Predicted climate change may significantly affect drinking water supply in urban areas. Local water stakeholders facing climate change will have to deal with uncertain information and unexpected events. To address this lack of data, the knowledge and experience of practitioners might be used to assess the potential impacts of climate change on different issues, including drinking water supply. This paper proposes a participatory tool to identify local issues associated with drinking water supply (from source to tap) in a climate change context. The tool consists in a participatory approach relying on the experience and knowledge of local practitioners. It also relies on multicriteria analysis. The approach was applied to the Québec City metropolitan area (Province of Quebec, Canada). It is based on assignment examples (in this case, a selected set of districts from the study territory) in order to generalize application to the entire territory. This approach helps stakeholders to rationally consider different dimensions and the complexity of drinking water supply.
\end{abstract}

Keywords: Climate Change, Drinking Water Supply, Participatory Approach, Relative Hazard Evaluation, Inference Technique

\section{Introduction}

Ensuring a supply of drinking water safe for human health and in sufficient quantity is a major issue for communities. In urban communities, drinking water supply is generally divided into several components: water supply source (denoted raw water source), treatment of raw water to produce drinking water and its flow from the water treatment plant to the consumer's tap. Climate change may directly or indirectly affect drinking water supply via its components (Bates et al. 2008; Delpla et al. 2009; Government of Canada 2004; Mailhot and Duchesne 2005; Meuleman et al. 2007).

That said, it is primarily extreme meteorological events (heavy rainfall, severe drought) that will affect drinking water supply in urban areas (Delpla et al. 2009; Mailhot and Duchesne 2005). Since it is difficult to predict these events and their frequency, duration and intensity in particular, each community must determine the vulnerability of its drinking water supply in order to anticipate and adapt to such events (Ouranos 2010a). However, the assessment of potential impacts of extreme events on drinking water supply and its vulnerability constitute a major challenge. First, uncertainties are associated with climate projections and extreme meteorological events (frequency, duration and intensity) more specifically (Mailhot and Duchesne 2005; US EPA 2011). Moreover, each component of drinking water supply constitutes 
a complex system which may be affected in different and multiple ways. As a result, the impacts of extremes events on these components are difficult to estimate.

Any evaluation of the potential impacts of climate change on drinking water supply thus requires important investments and human resources (data collection, modelling, etc.). In that context, it appears relevant to turn to local actors in order to evaluate the potential impacts of climate change on drinking water supply in specific conditions. Experts of water management have a valuable experience of the challenges and of the tools to overcome them when it comes to drinking water supply. They also have a comprehensive overview of the different cause-andeffects linkages of different sorts of impacts, including climatic event impacts, in a variety of contexts. This tends to favour research methods such as semi-direct interviews, questionnaire survey as efficient ways to get feedbacks from experienced practitioners (Canadian Council of Professional Engineers 2008; Hersh and Wernstedt 2002; Kreutzwizer et al. 2003). These approaches inform on perceptions of events, on technical means applied, on structural and contextual contingency, etc. A participatory approach, which involves interaction between at least two practitioners, also bears these advantages and has other benefits. By offering space and room to the sharing of experiences, focus groups contribute to a common understanding of water supply systems and of their vulnerability. They also put into perspective the complex human-environmental systems in which practitioners have to intervene (Haase 2013). This type of approach was applied in several studies focused on climate change (Haase 2013; Hung and Chen 2013; Mittal et al. 2013; Picketts et al. 2013).

On the other hand, participatory approach implies deferring on the practitioners' perceptions of hazards and of climate change issues. But this is also the interest of the approach: by reaching out to other practitioners and sharing their experiences and points of views, participants to the focus groups formalize their knowledge of the field of action. Through discussion, they identify interdependency between the many parts of the water supply system. The relevancy of these points of view depends on the proximity of the object of discussion and of data assigned to discussion. In other words, when discussions refer to concrete contexts of practice and to wellknown though sometimes incomplete set of data, participants of focus groups are able to produce a common representation of issues at stake regarding water management supply in a variety of specific contexts. These specific contexts become the frames into which the regular and common practices have to be adjusted in order to face the climate change challenges. Building on the concerns and knowledge of local actors offers the additional benefit of mobilizing local stakeholders to find collective solutions, thereby helping to validate strategies that would benefit local administrations and populations seeking to adapt locally to climate change (Hallegatte 2009).

In general, studies relying on local actor knowledge of water management (Canadian Council of Professional Engineers 2008; Hersh and Wernstedt 2002; Hung and Chen 2013; Kreutzwizer et al. 2003; Picketts et al. 2013) only focus on specific aspects of drinking water supply (e.g., vulnerability of water treatment infrastructures and raw water source. Moreover, the variability of drinking water supply vulnerability to extreme meteorological events within a given study area (e.g., in a municipality or drinking water distribution system) has been briefly considered.

Between 2010 and 2013, an action-research project was conducted to identify a methodological planning framework to address adaptation to climate change in the Quebec metropolitan area (Cloutier and Joerin 2012). This action-research project was divided into three phases: the first consisted of identifying the impacts of climate change at the local level; the second phase aimed 
at identifying priority areas for potential hazards associated with climate change (relative to transportation, drinking water or urban heat islands) ${ }^{1}$. Based on the areas determined as priorities, the last phase consisted in designing urban and architectural adaptations for residential neighbourhoods that would contribute to minimizing the negative impacts of potential climate change on the safety of infrastructures, as well as on the comfort and health of residents (Vachon et al. 2013).

The main objective of the study, exposed in the following pages and related to the second phase of the action-research project, was to provide local practitioners an operational tool that enable to integrate the issues of adaptation to climate change in their daily decisions and professional practices. This results in a so generic and non-data intensive tool for local practitioners to plan measures in order to reduce the relative vulnerability of different components and spatial features of their drinking water system and other infrastructure to climate change. The tool consists in a participatory approach relying on the experience and knowledge of practitioners, meaning the regular processes and activities that drinking water practitioners (managers, technicians, analysts, etc.) face with regard to drinking water management. In order to help the formalization of experiences and knowledge, the tool also relies on multicriteria analysis. This analysis helps to classify the different dimensions taken into account. It also facilitates analysis of imprecise, uncertain or incomplete information through inference. The application of the approach leads us to conclude that it is essentially the sharing of experiences which enables practitioners to better understand global issues and management options in the context of climate change.

\section{Case study}

This project was conducted in two cities in the Québec City metropolitan area: Québec City and the city of Lévis. These cities include seven surface drinking water distribution systems serving some 530,000 inhabitants (Fig. 1). The seven systems are supplied by four raw water sources (Montmorency River, St. Charles Lake, St. Lawrence River, Chaudière River) which differ in terms of water availability and quality, as well as by their associated anthropogenic pressure. Moreover, the systems differ in terms of type of water treatment, quantities of water produced and distribution characteristics (e.g., hydraulic regime, pipe characteristics and condition, presence of reservoir and re-disinfection during distribution). As a result, the quality of drinking water produced and its vulnerability to climate change may vary considerably between the systems. Furthermore, distribution characteristics (e.g., concentration of residual disinfectant, characteristics and conditions of pipes, water residence time in pipes) fluctuate within the systems affecting the spatial variability of drinking water quality at the consumer's tap. As a result, the vulnerability of drinking water quality to climate change may also vary within each system. In order to consider this spatial variability, the seven distribution systems were divided into 117 districts according to their hydraulic characteristics and sampling locations for regulatory drinking water monitoring.

The region under study has always been subject to important climatic variations during the year, with mean daily temperatures of air ambient ranging from $-16.8^{\circ} \mathrm{C}$ to $+24.2^{\circ} \mathrm{C}$ (Environnement Canada 2013), and different lengths of seasons (i.e., long winters and relatively short summers). Naturally, these temporal fluctuations involve important temporal variations in the quality of raw water. The major projected climate change effects for the study region are the increase in

\footnotetext{
${ }^{1}$ Hazard is defined as the probability (unquantified) of potential decrease of drinking water quality at the consumer's tap in relation with different climate events.
} 
mean temperatures $\left(2.5^{\circ}\right.$ to $3.8^{\circ} \mathrm{C}$ in winter; $1.9^{\circ} \mathrm{C}$ to $3.0^{\circ} \mathrm{C}$ in spring and summer; $2.0^{\circ} \mathrm{C}$ to $3.1^{\circ} \mathrm{C}$ in fall; based on the $25^{\text {th }}$ to $75^{\text {th }}$ percentiles of projections for 2050) and changes in variability according to the seasons (Ouranos 2010b). A rise in frequency of winter thaw events and freezethaw cycles is also expected. Higher average precipitations are anticipated in winter and spring. Climate change will also result in variations in the frequency, intensity and duration of extreme meteorological events (Ouranos 2010b). For example, the number of days with ambient temperatures above $30^{\circ} \mathrm{C}$ could be twice as high in 2020 to 2040 and six times as high in 2080 to 2100 (Hengeveld et al. 2005). An increase in the occurrence of intense rainfall is also anticipated for the region under study (Mailhot et al. 2007).

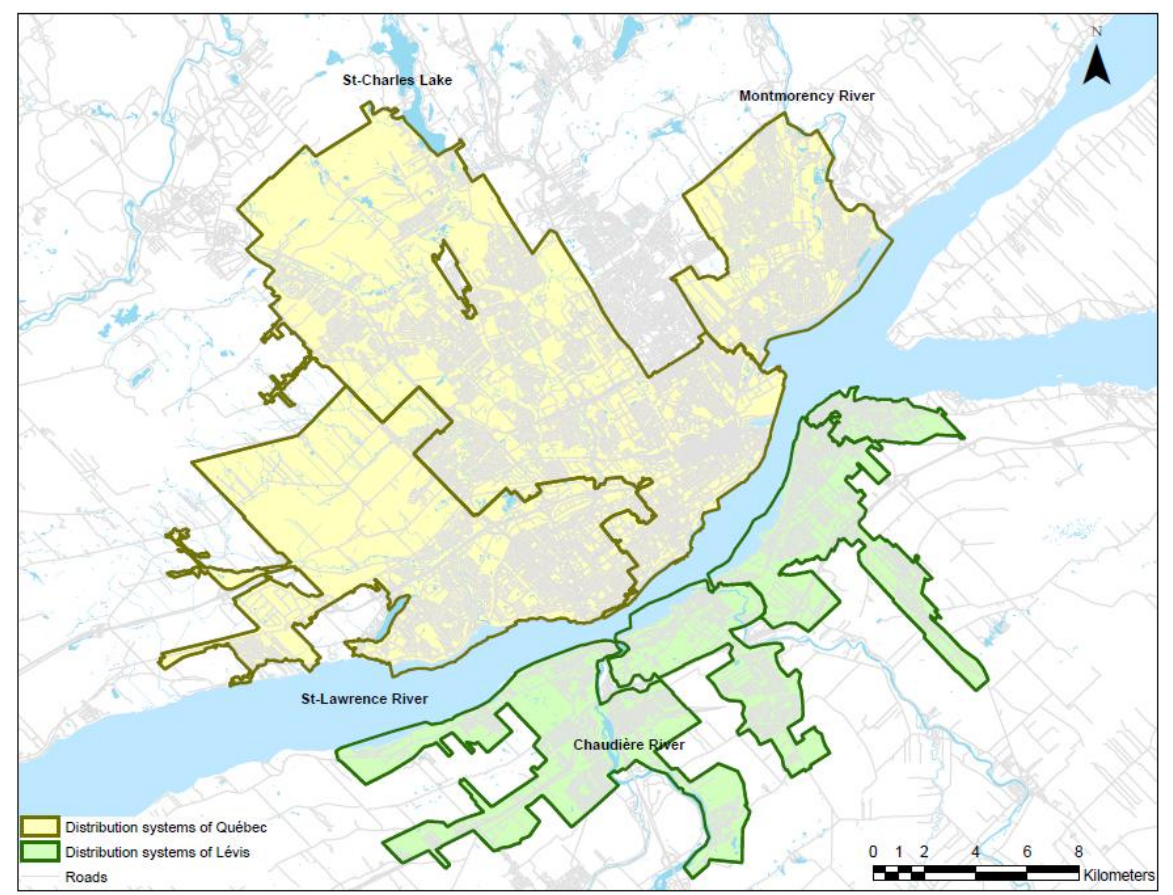

Fig. 1 Location of the seven distribution systems under study in Québec City and Lévis (QMC, Province of Quebec, Canada)

During the first phase of the action-research project, a participatory diagnosis of the Québec City metropolitan area highlighted the potential main impacts induced by climate change (Cloutier and Joerin 2012). Based on these findings, two hazards associated with drinking water supply were considered in this paper: 1 ) the potential decrease in drinking water microbiological quality at the consumer's tap and 2) the potential decrease in the availability of drinking water at the consumer's tap. These two hazards were investigated in three extreme meteorological contexts also selected according to local priorities: severe drought (SD), freeze-thaw cycles (FTC) and heavy rainfall (HR). The latter was not considered for the drinking water availability hazard. Multiple hazards and meteorological events were considered in this study mainly in order to observe the evolution of practitioner's reflection for different climate change contexts and issues.

\section{A participatory evaluation approach}

The objective of the proposed participatory approach was to enable local actors to identify drinking water supply issues on their territory, in association with climate change and to integrate these issues in their daily decisions and professional practices. The approach is divided 
into two main steps. The first step (the diagnostic) consists in the identification of the main issues for a specific hazard and meteorological context. The second step (the evaluation) aims to link these issues to the territory under study. Each step was carried out based on a focus group with local actors.

Since two hazards and three meteorological contexts were considered, the approach was applied in five analyses (Table 1).

Table 1 Description of relative hazard evaluation analyses carried out in the study

\begin{tabular}{lll}
\hline Analysis ID & Hazards & Meteorological contexts \\
\hline Analysis 1 & $\begin{array}{l}\text { Potential decrease in drinking water microbiological } \\
\text { quality at the consumer's tap }\end{array}$ & Severe drought (SD) \\
Analysis 2 & $\begin{array}{l}\text { Potential decrease in drinking water microbiological } \\
\text { quality at the consumer's tap }\end{array}$ & Heavy rainfall (HR) \\
Analysis 3 & $\begin{array}{l}\text { Potential decrease in drinking water microbiological } \\
\text { quality at the consumer's tap }\end{array}$ & Freeze-thaw cycles (FTC) \\
Analysis 4 & $\begin{array}{l}\text { Potential decrease in the availability of drinking water at } \\
\text { the consumer's tap }\end{array}$ & Severe drought (SD) \\
Analysis 5 & $\begin{array}{l}\text { Potential decrease in the availability of drinking water at } \\
\text { the consumer's tap }\end{array}$ & Freeze-thaw cycles (FTC) \\
\hline
\end{tabular}

\subsection{The diagnostic}

The hazards (concerning quality and availability of drinking water) may be influenced by factors related to drinking water supply components (raw water source, treatment and water distribution). For example, the impact of a meteorological event (e.g., severe drought) on water source quality and, consequently, drinking water quality at a consumer's tap will differ according to the type of water source supply (lake versus river). Types of water treatment processes and distribution infrastructure conditions in meteorological contexts may also influence the hazards. The proposed approach consists of comparing the relative hazard level between territorial districts based on hazard factor information.

The identification of hazard factors was conducted through literature and based on a focus group (in the five analyses) with local actors chosen for their expertise and their field experience at the local scale. At the time of the experiment, the five participants in the focus group had been working actively on drinking water management issues in specific parts of the territory under study for many years. More precisely, these actors were water plant managers, environmental advisors for local administrations or water management and hydraulic specialists. Participants were asked to identify (with several assumptions and simplifications) the most significant factors to evaluate each hazard for each meteorological context under study. No information on frequency, duration and intensity of the meteorological events was provided. The latter were to be considered in a global way. Thus, local actors had to base their appreciation on their knowledge and professional experience with extreme meteorological events in the territory under study. During the focus group, 19 factors were identified by local actors to assess relative hazards in the three meteorological contexts.

Among the hazard factors identified by local actors, some were not considered in the rest of the analyses because of their high correlation with other factors (i.e., the influence of a factor on hazards is explained by another factor) or their association with data not readily available (e.g., for confidentiality reasons) or inconsistent in quality for the entire territory. Disparities in data 
availability and quality within the territory under study were due mainly to the fact that the latter includes different municipalities supplied by different water treatment plants (with differences in operations, priorities and financial and human resources, etc.). The hazard factors used in next step (evaluation) are summarized in Table 2.

Table 2 List of factors selected by local experts to assess the relative hazards in three meteorological contexts

\begin{tabular}{|c|c|c|c|c|c|c|}
\hline Hazard factors & $\begin{array}{l}\text { Hazard } \\
\text { factor ID }\end{array}$ & Analysis 1 & Analysis 2 & Analysis 3 & Analysis 4 & Analysis 5 \\
\hline \multicolumn{7}{|l|}{ Raw water component } \\
\hline Water source supply & F01 & $x$ & $\mathrm{x}$ & & $\mathrm{x}$ & $\mathrm{x}$ \\
\hline Watershed size $\left(\mathrm{km}^{2}\right)$ & F02 & $x$ & $x$ & & & \\
\hline Drought history & F03 & $x$ & & & $x$ & \\
\hline \multicolumn{7}{|l|}{ Treatment component } \\
\hline $\begin{array}{l}\text { Type of water } \\
\text { treatment }\end{array}$ & F04 & $x$ & $x$ & & & \\
\hline $\begin{array}{lr}\text { Drinking } & \text { water } \\
\text { production } & \text { ratio }\end{array}$ & F05 & & & & & \\
\hline $\begin{array}{l}\text { (average day of } \\
\text { water volume }\end{array}$ & & & & & & \\
\hline $\begin{array}{l}\text { produced on } \\
\text { maximum capacity } \\
\text { of drinking water } \\
\text { utility) (\%) }\end{array}$ & & $x$ & $x$ & & $x$ & $x$ \\
\hline Drinking water & & & & & & \\
\hline \multicolumn{7}{|l|}{ transport component } \\
\hline $\begin{array}{l}\text { Drinking water pipe } \\
\text { material }\end{array}$ & F06 & $x$ & & $x$ & $x$ & $x$ \\
\hline $\begin{array}{l}\text { Number of water } \\
\text { pipe breaks (per } \\
\text { kilometer over } 10 \\
\text { years) }\end{array}$ & F07 & $\mathrm{x}$ & & $x$ & $x$ & $\mathrm{x}$ \\
\hline $\begin{array}{l}\text { Water consumption } \\
\text { indicator }\end{array}$ & F08 & $x$ & & & $x$ & \\
\hline $\begin{array}{l}\text { Seasonal residual } \\
\text { disinfectant } \\
\text { concentration }(\mathrm{mg} / \mathrm{L})\end{array}$ & F09 to F12 & $\mathrm{x}$ & $\mathrm{x}$ & $x$ & & \\
\hline
\end{tabular}

Once hazard factors have been identified by the local actors, the assessment of these factors on the studied territory can start. This operation requires the collection of data associated with each factor for each district of the seven distribution systems. Most of required data are available and owned by municipal and provincial institutions.

\subsection{The evaluation}

This step consists in the interaction and discussion between local actors about each of both hazards in the three meteorological contexts (Analyses 1 to 5) on the territory under study. More precisely, the local actors are asked to evaluate the relative hazards (Analyses 1 to 5 ) on the territory on the basis of the hazard factors previously selected. 
The entire territory, constituted of more than 100 districts different in water supply specificities, is too vast and too complex to be considered in a single evaluation. In order to reduce this complexity and to ease the participatory evaluation process, a case-based technique, often referred to as inference in multicriteria analysis literature (Chakhar and Saad 2012; Dias et al. 2002; Greco et al. 2001; Mousseau and Slowinski 1998), was applied. Inference consists in the use of a reduced set of assignment examples (here, several districts) in order to deduce the results for the whole study area (i.e., classify all districts on a relative hazard scale from the lowest relative hazard level to the highest relative hazard level).

The evaluation applied to the area under study involved four steps: 1) definition of hazard scale, 2 ) selection of assignment examples, 3) classification of assignment examples on hazard and 4) the generalization to the entire territory.

\subsubsection{Definition of hazard scale}

An ordinal relative hazard scale from the lowest relative hazard level to the highest relative hazard level was used to compare assignment examples according to the previously selected hazard factors. According to the classification of assignment examples carried out by local actors, a hazard relative level was assigned to each example. The number of levels was not limited and could vary according to the hazards and meteorological contexts. As shown in Table 3 , the number of relative hazard levels varies between analyses (from 4 to 6 ).

Table 3 Relative hazard levels assigned to assignment examples by the local experts

\begin{tabular}{llllll}
\hline $\begin{array}{l}\text { Assignments } \\
\text { examples }\end{array}$ & Analysis 1 & Analysis 2 & Analysis 3 & Analysis 4 & Analysis 5 \\
\hline District 1 & 4 & 6 & 5 & 2 & 3 \\
District 2 & 1 & 1 & 5 & 1 & 2 \\
District 3 & 6 & 2 & 1 & 5 & 1 \\
District 4 & 1 & 1 & 1 & 1 & 2 \\
District 5 & 1 & 1 & 3 & 1 & 2 \\
District 6 & 5 & 4 & 4 & 3 & 4 \\
District 7 & 5 & 3 & 2 & 4 & 4 \\
District 8 & 3 & 5 & 2 & 2 & 3 \\
District 9 & 6 & 2 & 4 & 6 & 1 \\
District 10 & 2 & 1 & 3 & 1 & 2 \\
\hline
\end{tabular}

\subsubsection{Selection of assignment examples}

As previously mentioned, assignment examples are used to animate the discussion between local actors about issues of drinking water supply and to compare the hazard (Analyses 1 to 5) on the territory. There are no formal rules that can be used to coherently identify the assignment examples. However, some general guidelines are followed to obtain the 'best' set of districts used as assignment examples. First, examples should be as representative of the territory as possible by including and covering different local specifications and geographical locations (i.e., representing different characteristics in terms of hazard factors found on the territory under study). Secondly, they should be non-redundant (in terms of their evaluation on the different factors). Thirdly, districts should cover all the decision classes; in other words, all hazard levels should be covered by at least one district. Finally and ideally, districts should be well known to the local actors in order to ensure that the assignments they provide were correct and coherent. 
About the number of selected examples, we observed that there was no ideal number of examples. In fact, a limited number of examples might lead to a few and very generic decision rules and, on the contrary, a too great number of examples may lead to a high number of very specific and redundant decision rules. In order to facilitate the discussion between actors and their assignments of examples on the hazard scale, we chose to select a limited number of examples. For these reasons and since the relatively small number of hazard factors selected and the low variability of several of these factors (e.g., water source, watershed size, type of water treatment, drinking water production ratio) on the study territory, ten districts were considered as relatively sufficient.

The districts used as assignment examples are illustrated in Figure 1. As observed in this figure, one assignment example is located in the distribution system outside of the teritory under study which should be originally considered. But for logistical reasons, this system was not considered. Since this system is relatively similar in term of drinking water supply specificities that one of the study seven systems, this assignment example district was still selected.

\subsubsection{Classification of assignment examples}

A second focus group (bringing together with the same local actors) met to compare the assignment examples (i.e., ten districts) in terms of hazard. After discussion and that a consensus had been reached, the local actors had to position the representative on the relative hazard scale from the lowest hazard level to the highest hazard level for each analysis (Analyses 1 to 5). From the theoretical point of view of the case-based reasoning, actors should assign districts based on their territorial knowledge and expertise and using data associated with hazard factors.

Irrespective of the analysis, the local actors focused primarily on several hazard factors they viewed as the most significant to compare districts in terms of relative hazard level. This is due to the fact that human beings, in general, cannot deal with a large number of comparison criteria at the same time, as underlined by Yang and Huang (2000); they implicitly choose a subset of criteria deemed the most important to them. Generally, the hazard factors which were the most used by local actors to guide their reflections and discussions represent parameters which actors are the most familiar. Moreover, it is important to note that actors were able to classify the districts one to another on the hazard relative scale (i.e., higher versus lower hazard) but they could not decide on a quantification of the hazard (i.e., high or low hazard).

For each analysis, results of the assignment process (i.e., assignment of each assignment example on the hazard scale) are provided in Table 3. For instance, in the case of a potential decrease in drinking water microbiological quality at the consumer's tap (Analysis 1 ) in a severe drought context, the local actors judged that districts 4 and 5 should be assigned the lowest relative hazard level (i.e., relative hazard level=1). They judged that districts 3 and 9 should be assigned the highest hazard level (i.e., relative hazard level=6). 


\section{The highest hazard

 \\ District 6 \\ District 9 \\ District 5|District 10 \\ District 7 \\ District 8 \\ District 4 \\ District 3 \\ The lowest hazard}

Fig. 2 Classification of assignment examples on the relative hazard open scale by the local actors during the evaluation step for the Analysis 3 (Quality - FTC)

Generalization to the territory under study

In this step, the Dominance-based Rough Set Approach (DRSA) (Greco et al. 2001) was used to infer a set of decision rules that summarize the information provided by the local actors. In other words, the objective is to reproduce, as closely as possible, with the interfered set of decision rules, the classification resulting from the actor's evaluation. The main input of DRSA is the hazard factor data associated with each assignment example and their classification on the relative hazard scale provided by the local actors. The output is a set of decision rules for each analysis (i.e., for each hazard in each of the three meteorological contexts). Detailed information on DRSA is available in other papers (Chakhar and Saad 2012; Greco et al. 2001).

The inferred decision rules were used to classify all districts of the territory under study for each analysis. The result of the classification was then provided as input to a geographical information system, in this case ArcGIS (Version 10.0) in order to generate the relative hazard map for each analysis. For illustrative purposes, two maps corresponding to the results of two of the five analyses (Analyses 3 and 5) are presented in Fig. 3.

\section{Discussion}

As previously mentioned, the objective of this paper was to propose an approach to enable local actors to identify drinking water supply issues within their territory with available data. For this reason, the discussion focuses mainly on the participatory approach and not on the results of its application.

\subsection{What we have learned from the focus groups}

The diagnosis and evaluation steps provided information on practices and needs. It would appear that each meteorological event is analyzed and processed individually in its specific context. Through a discussion platform, such as a focus group - but it could also be a web platform, for example - local actors can recognize and identify causal-loops between events, contexts or methods. This can lead to a broader understanding and a common representation of the issues at stake, and of ways to address climate change adaptation. 
(a)

(b)

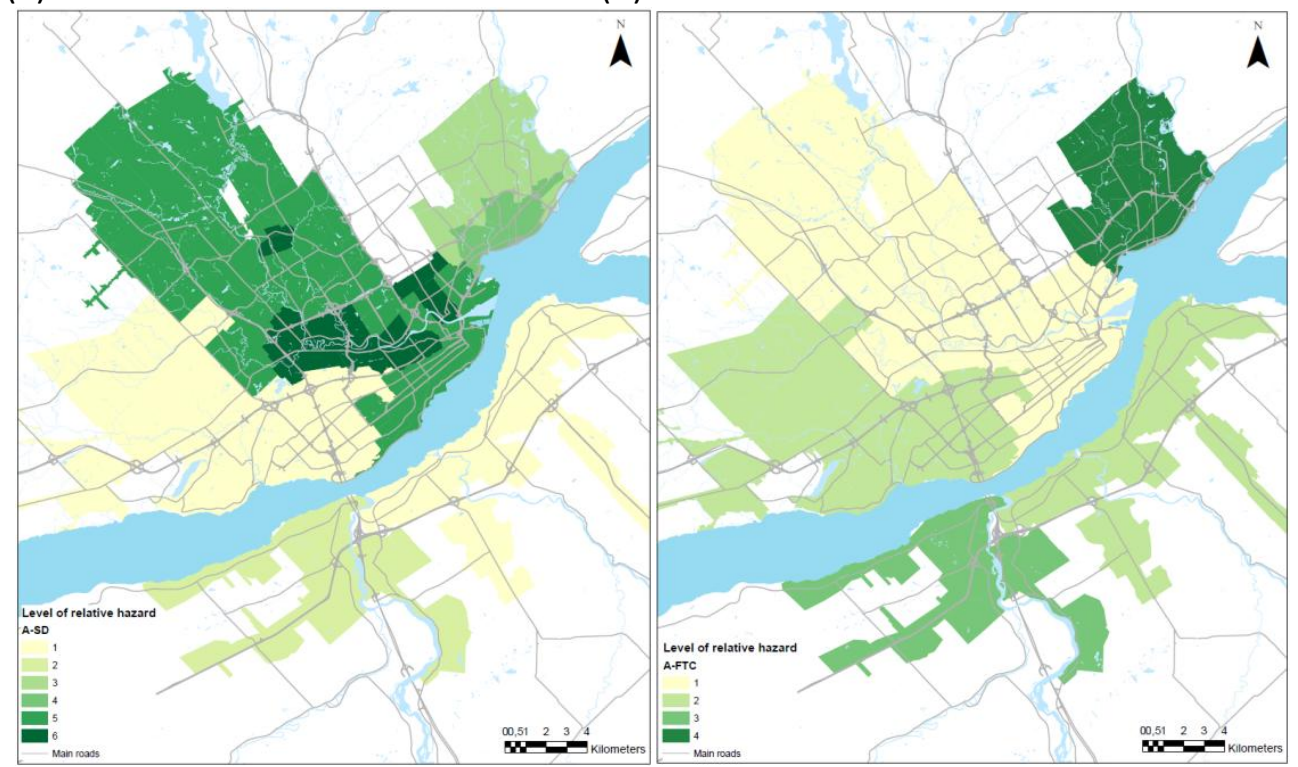

Fig. 3 Relative hazard maps: (a) Probability of the potential decrease in drinking water microbiological quality at the consumer's tap (Q): Analysis 3 and for (b) Probability of the potential decrease in the availability $(A)$ of drinking water at the consumer's tap: Analysis 5 in a freezethaw cycle (FTC) context

Moreover, local actors refer to data they understand and somewhat control. This is especially true when they are asked to classify existing districts according to their vulnerability or, more generally, their characteristics. When confronted with a decision to be made, local actors rely on what they know best and on data they trust. This can limit the precision of the resulting analysis. But it also expands its relevance for the practice. Furthermore, this approach does not exclude using new information and data to inform the decision process. However, it argues in favour of a framework that ensures that local actors (and users more generally) do understand the data and will be able to integrate them into their water management practices.

In general, the focus groups attest to the relevance of the discussion process to fill in some gaps of information in a context where practitioners do not have all the information in hand (Haase 2013). Moreover, focus groups are flexible, simple and inexpensive (Morgan 1997).

The efficiency of DRSA to generalize the hazard's evaluation of several districts to a territory under study raises questions, especially given the purpose of identifying a reproducible planning framework for local adaptation to climate change. Local administrations of different sizes and resources were not necessarily able to equally apply such a complicated tool in their adaptation planning process.

In brief, the proposed participatory approach implies deferring to the local actor's perceptions of hazards and climate change issues. Also, local actors do not quantify the hazards (i.e., absolute hazards) on the study territory. However, by reaching out to other practitioners and sharing their experiences and opinions in focus groups, they formalize their knowledge of the field of action. This is why the approach is interesting. Through discussion, they can identify interdependencies between the many parts of the drinking water supply system. The relevancy 
of these points of view depends on the proximity of the object of discussion and data assigned to discussion. In other words, when discussions refer to concrete contexts of practice and wellknown, although sometimes incomplete sets of data, participants in focus groups are able to produce a common representation of issues at stake in water management supply in a variety of specific contexts. These specific contexts become the frameworks for which standard and common practices must be adjusted in order to face climate change challenges. Building on the concerns and knowledge of local actors offers the additional benefit of mobilizing local stakeholders to find collective solutions, thereby helping to validate strategies that would benefit local administrations and populations seeking to adapt locally to climate change (Hallegatte 2009).

\subsection{What we have learned from relative hazard maps}

In cases where technical and human resources make it possible to achieve multi-criteria analysis (e.g., using DRSA), the type of maps produced with the relative hazard evaluation approach presented in this paper can help decision makers identify priority areas for adaptation associated with drinking water supply (e.g., infrastructure rehabilitation, promotion of the drinking water-saving). For example, areas associated with the highest hazard level (or even the two highest levels according to the number of concerned areas) may be considered as adaptation priorities. However, several limitations in the application of the approach presented in this paper should be noted. First, the variability of relative hazard levels at a distribution system scale is relatively difficult to evaluate based on the results obtained (except for the Analysis 3). This is due mainly to the strong influence of raw water and treatment component factors (in comparison to factors associated with water transport) on the relative hazard level in the three meteorological contexts when the entire territory under study is considered. As a result, the study scale used in this paper is probably too large (different municipalities including different distribution systems). Moreover, since Québec City and Lévis represent a large territory, the use of only ten assignment examples is, finally, probably not sufficient to represent the entire range of hazard factor data that might be found within this territory. These results demonstrate the importance to consider the context of the project (e.g. the objectives of the study, the governance context) in the selection/choice of one study scale. This approach could easily be re-applied to Québec City and Lévis on a smaller scale. For example, the same type of analyses could be carried out, but for each distribution system (i.e., on an individual basis). For this purpose, the district used as assignment examples should be located in the same distribution system. As a result, the maps of the relative hazard level obtained from this (second) hazard evaluation, at a smaller scale, would identify the priority areas for adaptation within each system.

\section{Conclusions}

Faced with climate change, local actors must deal with uncertain information and unexpected events. This paper presents a participatory approach to identify local issues associated with drinking water supply in a context of climate change. The analysis allows consideration of consistently different dimensions of drinking water supply within the territory based on available data, assignment examples (in this case, a selected set of districts from the study territory) and local field experts' experience.

The participatory approach illustrated in this paper may easily be applied and adapted to other fields of study and territories. It would interesting to compare the focus group results with other 
focus groups within the same territory, in order to identify which type of data and information are relevant to local practitioners.

\section{Acknowledgments}

The authors wish to thank the Ouranos Consortium (http://www.ouranos.ca/en/) for supporting this study under the Climate Change and Urban Transformation Research-Action Project. The authors wish also to express their gratitude to Natural Resources Canada (http://www.nrcan.gc.ca/) and the Fonds Vert Québec (http://www.mddep.gouv.qc.ca/). The authors would also like to thank Martial Labarthe, Dominique Viens, Jean-Philippe Labbé-Tremblay, Catherine Dubois and Martin Laliberté, our colleagues and members of the Action-Research Project. Finally, authors are indebted to all the experts who took part in the different meeting sessions for their unfailing and crucial feedback, and to the people who contributed to the data collection.

\section{Reference}

Bates BC, Kundzewics ZW, Wu S, Palutikof JP (eds) (2008) Climate change and water. technical paper of the intergovernmental panel on climate change. Intergovernmental Panel on Climate Change (IPCC), Geneva, Switzerland

Canadian Council of Professional Engineers (2008) Adapting to climate change: Canada's first national engineering vulnerability assessment of public infrastructure. ON, Canada

Chakhar S, Saad I (2012) Dominance-based rough set approach for groups in multicriteria classification problems. Decis Support Syst 54:372-380. doi:10.1016/j.dss.2012.05.050

Cloutier G, Joerin F (2012) Tackling climate change adaptation at the local level through community participation. In: Holt WG (ed) Research in urban sociology, vol 12. Emerald Group Publishing Limited, Bingley, pp 51-73

Delpla I, Jung AV, Baures E, ClementM, Thomas O (2009) Impacts of climate change on surface water quality in relation to drinking water production. Environ Int 35:1225-1233. doi:10.1016/j.envint.2009.07.001

Dias L, Mousseau V, Figueira J, Climaco J (2002) An aggregation/disaggregation approach to obtain robust conclusions with ELECTRE TRI. Eur J Oper Res 138:332-348. doi:10.1016/S03772217(01)00250-8

Environnement Canada (2013) Normales et moyennes climatiques au Canada 1971-2000. Service météorologique du Canada.

http://climate.weather.gc.ca/climate normals/index f.html. Accessed 11 December 2013

Lemmen DS, Warren FJ (eds) (2004) Climate change impacts and adaptation: a canadian perspective. Government of Canada, ON, Canada

Greco S, Matarazzo B, Slowinski R (2001) Rough sets theory for multicriteria decision analysis. Eur J Oper Res 129:1-47. doi:10.1016/S0377-2217(00)00167-3

Haase D (2013) Participatory modelling of vulnerability and adaptive capacity in flood risk management. Nat Hazards 67:77-97. doi:10.1007/s11069-010-9704-5 
Hallegatte S (2009) Strategies to adapt to an uncertain climate change. Glob Environ Chang 19:240-247. doi:10.1016/j.gloenvcha.2008.12.003

Hengeveld H, Whitewood B, Fergusson A (2005) An introduction to climate change: a canadian perspective. ON, Canada

Hersh R,Wernstedt K (2002) Gauging the vulnerability of local water systems to extreme events. J Environ Plan Manag 45:341-361. doi:10.1080/09640560220133397

Hung H-C, Chen L-Y (2013) Incorporating stakeholders' knowledge into assessing vulnerability to climatic hazards: application to the river basin management in Taiwan. Clim Chang 120:491-507. doi:10.1007/s10584-013-0819-z

ISSMGE (2004) Glossary of risk assessment terms - Version 1. Technical Committee on Risk Management (TC32) of the International Society of Soil Mechanics and Geotechnical Engineering (ISSMGE).

http://140.112.12.21/issmge/2004Glossary_Draft1.pdf. Accessed 11 December 2014 Kreutzwiser R, Moraru L, de Loë R, Mills B, Schaefer K (2003) Drought sensitivity of municipal water supply systems in Ontario. Great Lakes Geogr 9:59-70

Mailhot A, Duchesne S (2005) Impacts et enjeux liés aux changements climatiques en matière de gestion des eaux en milieu urbain. Vertigo - La revue en sciences de l'environnement Hors-série 2:1-9. doi:10.4000/vertigo.1931

Mailhot A, Duchesne S, Caya D, Talbot G (2007) Assessment of future change in IntensityDuration-Frequency (IDF) curves for southern Quebec using the Canadian Regional ClimateModel (CRCM). J Hydrol 347:197-210.

doi:10.1016/j.jhydrot.2007.09.019

Meuleman AFM, Cirkel G, Zwolsman GJJ (2007) When climate change is a fact! Adaptive strategies for drinking water production in a changing natural environment. Water Sci Technol 56:137-144. doi:10.2166/Wst.2007.545

Mittal N, Mishra A, Singh R (2013) Combining climatological and participatory approaches for assessing changes in extreme climatic indices at regional scale. Clim Chang 119:603-615. doi:10.1007/s10584-013-0760-1

Morgan DL (1997) Focus groups as qualitative research, 2nd edn. Sage, London Mousseau V, Slowinski R (1998) Inferring an ELECTRE TRI model from assignment examples. J Glob Optim 12:157-174. doi:10.1023/A:1008210427517

Ouranos (2010) Savoir s'adapter aux changements climatiques. Montréal, QC, Canada

Pampalon R, Gamache P, Hamel D (2010) Indice de défavorisation matérielle et sociale du Québec: suivi méthodologique de 1991 à 2006. Publication de l'Institut Nationale de Santé du Publique du Québec, Canada 
Picketts IM, Curry J, Dery SJ, Cohen SJ (2013) Learning with practitioners: climate change adaptation priorities in a Canadian community. Clim Chang 118:321-337. doi:10.1007/s10584012-0653-8

US EPA (2011) Climate change vulnerability assessments: four case studies of water utility practices. Global Change Research Program, National Center for Environmental Assessment, United States Environmental Protection Agency (US EPA), Washington, DC, USA

Vachon G, ChouinardMN, Cloutier G, Dubois C, Després C (2013) Adapting cities to climate change: an action-research approach to imagining design solutions, measuring their feasibility and acceptability, and informing decision. Enquiry/ARCC J Archit Res 10:14-28

Yang C, Huang J-B (2000) A decision model for IS outsourcing. Int J Inf Manag 20:225-239. doi:10.1016/S0268-4012(00)00007-4 